\title{
Diagnostic markers of urothelial cancer based on DNA methylation analysis
}

Yoshitomo Chihara ${ }^{1,2^{*}}$, Yae Kanai ${ }^{3}$, Hiroyuki Fujimoto ${ }^{4}$, Kokichi Sugano $^{5}$, Kiyotaka Kawashima ${ }^{6}$, Gangning Liang $^{7}$, Peter A Jones ${ }^{7}$, Kiyohide Fujimoto $^{1}$, Hiroki Kuniyasu ${ }^{2}$ and Yoshihiko Hirao ${ }^{1}$

\begin{abstract}
Background: Early detection and risk assessment are crucial for treating urothelial cancer (UC), which is characterized by a high recurrence rate, and necessitates frequent and invasive monitoring. We aimed to establish diagnostic markers for UC based on DNA methylation.

Methods: In this multi-center study, three independent sample sets were prepared. First, DNA methylation levels at CpG loci were measured in the training sets (tumor samples from 91 UC patients, corresponding normal-appearing tissue from these patients, and 12 normal tissues from age-matched bladder cancer-free patients) using the lllumina Golden Gate methylation assay to identify differentially methylated loci. Next, these methylated loci were validated by quantitative DNA methylation by pyrosequencing, using another cohort of tissue samples (Tissue validation set). Lastly, methylation of these markers was analyzed in the independent urine samples (Urine validation set). ROC analysis was performed to evaluate the diagnostic accuracy of these 12 selected markers.
\end{abstract}

Results: Of the 1303 CpG sites, 158 were hyper ethylated and 356 were hypo ethylated in tumor tissues compared to normal tissues. In the panel analysis, 12 loci showed remarkable alterations between tumor and normal samples, with $94.3 \%$ sensitivity and $97.8 \%$ specificity. Similarly, corresponding normal tissue could be distinguished from normal tissues with $76.0 \%$ sensitivity and $100 \%$ specificity. Furthermore, the diagnostic accuracy for UC of these markers determined in urine samples was high, with 100\% sensitivity and 100\% specificity.

Conclusion: Based on these preliminary findings, diagnostic markers based on differential DNA methylation at specific loci can be useful for non-invasive and reliable detection of UC and epigenetic field defect.

Keywords: Urothelial cancer, DNA methylation, Pyrosequencing, ROC, Piagnostic accuracy

\section{Background}

According to the American Cancer Society estimates for 2013, bladder cancer will account for 72,570 newly diagnosed cases and 15,210 deaths [1]. Bladder cancers can be classified into two groups based on histopathology and clinical behavior: non-muscle-invasive urothelial cancer (NMIUC: pTa-pT1) and muscle-invasive urothelial cancer (MIUC: pT2-pT4). NMIUCs represent approximately $80 \%$ of newly diagnosed bladder cancer cases and are treated by transurethral resection (TUR). However, $70 \%$ of the treated cases recur, and of these $15 \%$ progress to invasive

\footnotetext{
* Correspondence: yychihara@gmail.com

'Department of Molecular Pathology, Nara Medical University, 840,

Shijyo-cho, Kashihara, Japan

2Department of Urology, Nara Medical University, 840, Shijyo-cho, Kashihara, Japan

Full list of author information is available at the end of the article
}

cancers [2]. Consequently, the follow-up for NMIUC includes lifelong cystoscopy monitoring every few months. MIUC usually requires radical cystectomy and has a poor prognosis [3]. Although cystoscopy and cytology are the gold standard for diagnosing bladder cancer, cystoscopy is an invasive procedure and cytology has poor sensitivity for detecting low grade tumors [4]. It is therefore crucial to develop reliable and non-invasive early diagnostic markers to improve strategies for management of bladder cancer patients.

Genetic and epigenetic factors are known to contribute to the occurrence of bladder cancer [2]. Hence, several DNA-based urinary markers have been evaluated with the aim of reducing the need for cystoscopy and improving the accuracy of tumor detection. However, none have been proven to be sufficiently reliable in

\section{Biomed Central}


detecting the entire spectrum of bladder cancers in the clinic [5].

Among the recently developed diagnostic markers for bladder cancers, those based on aberrant DNA methylation appear to be highly promising. Recent findings have indicated that epigenetic silencing associated with various cancers may involve DNA methylation extending over a large chromosomal region, often described as genome-overall hypomethylation or regional hypermethylation [6,7]. Diagnostic indicators based on DNA methylation have potential advantages over other genetic markers because DNA methylation occurs widely in cancer cells and consistently affects the same promoter regions. Therefore, a minimal analysis using a few loci is sufficient for diagnosis [8]. Furthermore, there is accumulating evidence that aberrant DNA methylation occurs frequently and early in human carcinogenesis $[9,10]$. Several studies on bladder cancer have indicated that tumor-specific DNA methylation markers have higher sensitivity and specificity than the parameters used in cytological urine analysis $[11,12]$. However, when used in highly sensitive, quantitative analytical techniques for measuring DNA methylation in urine samples, these markers tend to lose their both sensitivity and specificity for cancerous cells [13-15]. One of the reasons for this could be that aberrant DNA methylation occurs in non-cancerous tissue also due to aging, smoking and environmental factors [6]. Secondly, both cancer cells and normal transitional cells shed in the urine may have altered DNA methylation because of concomitant conditions, especially chronic inflammation and/or persistent infection [16], or the urine samples may be contaminated with other types of cells. Moreover, most studies analyzed a region within a CpG island (CGI) that may be altered in its methylation status, but may not affect gene expression in non-cancerous regions. Quantitative DNA methylation methods are advantageous as these can detect pre-malignant epigenetic field defects that cannot be revealed by histological examinations.

We previously reported aberrant DNA methylation occurring in urothelial cancer (UC) through a genomewide approach [17]. The aim of the present study was to select and validate markers based on UC-specific regional aberrant DNA methylation. The association of UC with aberrant DNA methylation in selected loci was analyzed statistically by comparison of malignant and normal urothelial tissues. Lastly, we assessed the clinical relevance of the identified markers for detecting UC using urine samples.

\section{Methods}

\section{Sample collection and preparation}

Tissue samples were collected at 4 participating centers following protocols approved by an institutional review board: (1) University of Southern California, Norris Comprehensive Cancer Center, and 3 Japanese institutions, (2) Nara Medical University, Nara, (3) National Cancer Center Hospital, Tokyo, and (4) Tochigi Cancer Center Hospital, Tochigi. Informed consent was obtained from all participants at the respective institutions, and this study was approved by Nara Medical University Medical Ethics Committee as the project name "Epigenetic profiling and diagnostic markers of urogenital cancer based on DNA methylation analysis" from October 5, 2010.

Tissue samples of tumor and corresponding normalappearing tissue adjacent to the tumor were obtained from UC patients during the surgical procedure (TUR or radical cystectomy). Corresponding normal-appearing tissue were judged macroscopically or endoscopically and dissected. A half of tissues were taken pathological examination, if the tissue included cancer, the section was excluded for the analyses. Control tissue samples of normal urothelia were obtained from patients without UC. Tumors were staged according to the UICC 1987 TNM Classification system [18]. All collected tissues were frozen and stored at $-80^{\circ} \mathrm{C}$ until use for DNA extraction.

Urine samples were collected from UC patients before surgery and from healthy volunteers by spontaneous urination. Voided urine samples $(50 \mathrm{~mL})$ were centrifuged at $2000 \times \mathrm{g}$ for $10 \mathrm{~min}$, and the pelleted urine sediment was rinsed twice with phosphate-buffered saline (PBS) and stored until use for DNA extraction.

DNA was extracted using conventional extraction methods [19]. DNA (2 $\mu \mathrm{g})$ was treated with sodium bisulfite using Epitect Bisulfite Kit (Qiagen) according to the manufacturer's protocol and resuspended in $40 \mu \mathrm{L}$ of distilled water for subsequent use.

Samples of urothelial tissue from UC patients $(n=144)$, adjacent normal appearing urothelia $(n=59)$ and patients without UC ( $\mathrm{n}=33)$ were divided into different experimental groups in order to generate sets for training and validation (Table 1). Samples of urine sediments from UC patients $(n=73)$ and healthy volunteers $(n=18)$ were analyzed as an independent validation sets. Samples collected from the 4 participating centers were distributed for identification of UC-specific DNA methylation and then for validation (Figure 1).

\section{DNA methylation profiling using universal beads ${ }^{\mathrm{TM}}$ array}

In our previous study, DNA methylation profiling was performed using the GoldenGate Methylation Cancer Panel I (Illumina Inc., La Jolla, CA) at the USC Epigenome Center [17]. In this study, the data were reanalyzed with the same platform for selected CpG sites from regions of aberrant DNA methylation specifically associated with tumors. The array interrogated 1,505 CpG sites selected from 807 cancer-related genes. The data were first 
Table 1 Clinical characteristics of UC and control patients

\begin{tabular}{|c|c|c|c|}
\hline & $\begin{array}{l}\text { Training } \\
\text { set }\end{array}$ & $\begin{array}{c}\text { Tissue } \\
\text { validation set }\end{array}$ & $\begin{array}{c}\text { Urine } \\
\text { validation set }\end{array}$ \\
\hline $\begin{array}{l}\text { Control patients } \\
(\mathbf{n}=\mathbf{5 1})\end{array}$ & $12(\mathrm{~N})$ & $21(\mathrm{~N})$ & $18(\mathrm{NU})$ \\
\hline $\begin{array}{l}\text { Age, median } \\
\text { (range) (years) }\end{array}$ & $63(50-80)$ & $62(27-82)$ & $54(16-77)$ \\
\hline Male/female & $12 / 0$ & $13 / 8$ & $6 / 12$ \\
\hline $\begin{array}{l}\text { UC patients } \\
(\mathbf{n}=\mathbf{2 1 7})\end{array}$ & $91(\mathbf{T})$ & $53(\mathrm{~T})$ & $73(\mathrm{TU})$ \\
\hline $\begin{array}{l}\text { Age, median } \\
\text { (range) (years) }\end{array}$ & $66(40-91)$ & $69(49-85)$ & $69(36-88)$ \\
\hline Male/female & $80 / 11$ & $42 / 11$ & $59 / 14$ \\
\hline $\begin{array}{l}\text { Tumor-adjacent } \\
\text { normal tissue }\end{array}$ & $34(\mathrm{CN})$ & $25(\mathrm{CN})$ & - \\
\hline \multicolumn{4}{|l|}{$\begin{array}{l}\text { Tumor Stage in } \\
\text { UC patients }\end{array}$} \\
\hline $\mathrm{Ta}$ & 20 & 2 & 7 \\
\hline $\mathrm{T} 1$ & 32 & 16 & 30 \\
\hline T2 & 13 & 9 & 24 \\
\hline T3 & 20 & 21 & 10 \\
\hline $\mathrm{T} 4$ & 6 & 5 & 2 \\
\hline \multicolumn{4}{|l|}{$\begin{array}{l}\text { Tumor Grade in } \\
\text { UC patients }\end{array}$} \\
\hline G1 & 5 & 0 & 5 \\
\hline G2 & 38 & 25 & 32 \\
\hline G3 & 48 & 28 & 36 \\
\hline
\end{tabular}

*Samples of normal-appearing tissue adjacent to the tumor were collected from UC patients for each set. Abbreviations: $N$ normal urothelial tissue, $C N$ corresponding normal-appearing tissue adjacent to the tumor in UC patients, $T$ tumor tissue, $N U$ urine sediments from healthy volunteers, $T U$ urine sediments from UC patients.

Urothelial tissue samples were collected during surgical procedures from UC and control patients. Urine samples were collected from UC patients and healthy volunteers. Samples were divided into experimental groups as given.

analyzed using the BeadStudio Methylation software (Illumina Inc., La Jolla, CA), and then a supervised cluster analysis with correlation metrics and average linkage was carried out using the open-source program Cluster 3.0. A $\beta$ value of 0 to 1.0 was reported for each CpG site signifying percent methylation from $0-100 \%$, respectively. The $\beta$ values were calculated by subtracking background using negative control on the array and calculating the ratio of the methylated signal intensity to the sum of both methylated and unmethylated signals plus a constant of 100. Measurements with detection $\mathrm{p}>0.05$ were marked missing.

\section{Bisulfite pyrosequencing}

DNA methylation status of candidate tumor-specific hyper- or hypo-methylated CpG sites was assessed by pyrosequencing (PSQ) using Pyrosequencing 96HS (Biotage, Uppsala, Sweden) and PyroMark Q24 (Qiagen) according to the manufacturer's protocol. To enable single-strand preparation, the reverse primer was $5^{\prime}$ biotinylated. Reaction volumes of $30 \mu \mathrm{l}$ contained $5 \times$ GoTaq buffer, 1.5 units GoTaq Hot Start Polymerase (Promega), $1 \mu \mathrm{M}$ of primers, and $500 \mathrm{nM}$ of dNTPs. PCR conditions were as follows: $95^{\circ} \mathrm{C}$ for $3 \mathrm{~min}$; 45 cycles of $95^{\circ} \mathrm{C}$ for $30 \mathrm{~s}$, the respective annealing temperature for $30 \mathrm{~s}$, and $72^{\circ} \mathrm{C}$ for $30 \mathrm{~s}$; and a final extension step at $72^{\circ} \mathrm{C}$ for $4 \mathrm{~min}$. PCR primer sequences are given in Table 2. PSQ primers were designed to include $\mathrm{CpG}$ or near-CpG regions within 300 bps that were assayed on the Illumina GoldenGate Panel.

\section{Immunohistochemistry}

The immunohistological studies of SOX1, TJP2, VAMP8 and SPP1 were carried out on formalin fixed, paraffin embedded tissue samples, of which 5 normal tissues and 53 tumor tissues in the training set as described previously [19]. The primary antibodies were polyclonal rabbit anti-SOX1 (Abcam Inc., diluted at 1:500), polyclonal rabbit anti-TJP2 (kindly provided by Dr. Masuo Kondo, Graduate School of Pharmaceutical Sciences, Osaka University, Japan), monoclonal rabbit antiVAMP8 (Abcam Inc., diluted at 1:100) and monoclonal rabbit anti-SPP1 (Abcam Inc., diluted at 1:100). Immunoreactivity was evaluated according to modified Allered's score system [20]. Briefly, the score represented the estimated proportion of positively stained cells $(0=$ none, $1=$ less than $1 / 100,2=1 / 100$ to less than $1 / 10$, $3=1 / 10$ to less than $1 / 3,4=1 / 3$ to less than $2 / 3$, and $5=2 / 3$ or above). The staining intensities were averaged from the positive cells $(0=$ none, $1=$ weak, $2=$ intermediate, and $3=$ strong). The product of these scores served as the total score. All results were scored by one of the authors (H. K.) without prior knowledge of the DNA methylation status.

\section{Statistical analysis}

Graphpad Prism version 4.02 was used for performing the Mann-Whitney $U$ test, calculating receiver operating characteristics (ROC) for sensitivity and specificity of the candidate loci and Pearson's correlation coefficient.

\section{Results}

Identification of candidate UC-specific aberrant DNAmethylated CpG Sites

In our previous study, differentially methylated regions had been identified in DNA samples from normal and UC urothelial tissues [17]. In the present study, as a first step, tumor-specific, aberrant DNA methylation sites were identified within $\mathrm{CpG}$ loci. DNA methylation profiling was compared between 3 groups of tissue samples (Figure 2): normal urothelial tissue $(\mathrm{N}, \mathrm{n}=12)$, corresponding normal-appearing tissue adjacent to the tumor in $\mathrm{UC}$ patients $(\mathrm{CN}, \mathrm{n}=34)$, and tumor samples saved 


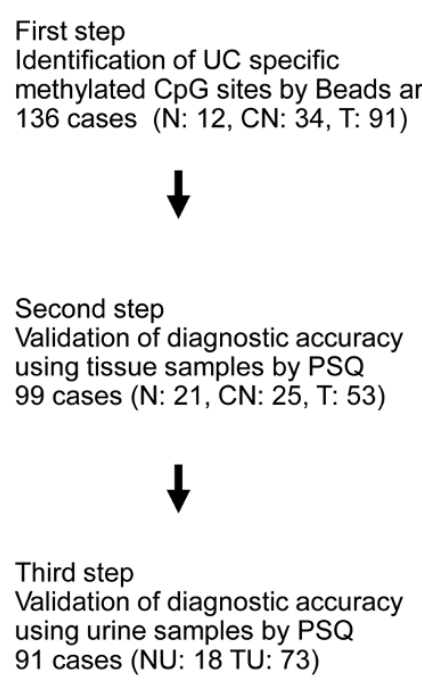

First step

Identification of UC specific methylated $\mathrm{CpG}$ sites by Beads array 136 cases (N: 12, CN: 34, T: 91)

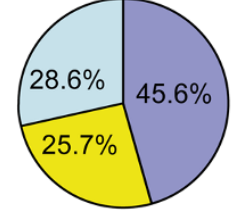

Second step

Validation of diagnostic accuracy using tissue samples by PSQ 99 cases (N: $21, \mathrm{CN}: 25, \mathrm{~T}: 53)$

Validation of diagnostic accuracy 91 cases (NU: 18 TU: 73)
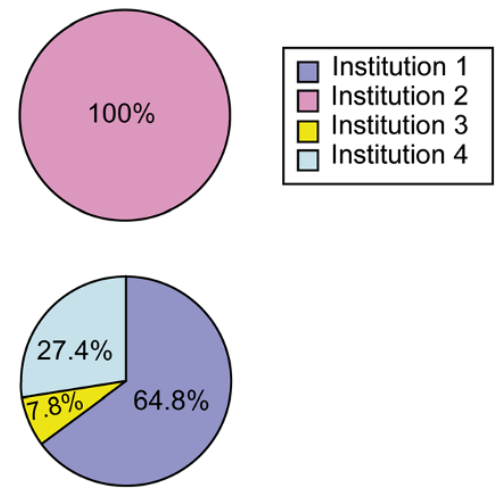

Figure 1 Study design. Samples of urothelial tissues and urine collected the indicated participating centers and distributed for identification of UC-specific DNA-methylation sites (First step) and validation of diagnostic accuracy (Second and Third steps) as indicated. N: normal urothelia, CN: corresponding normal-appearing tissue adjacent to tumor from UC patient, T: tumor samples from UC patients; NU: urine from normal participants, TU: urine from UC patients treated by transuretheral resection; PSQ: pyrosequencing. Institution 1: Department of Urology, Norris Comprehensive Cancer Center, University of Southern California. Institution 2: Urology Division, National Cancer Center Hospital, Tokyo. Institution 3: Department of Urology, Nara Medical University. Institution 4: Department of Urology, Tochigi Cancer Center Hospital.

during TUR procedure on UC patients $(\mathrm{T}, \mathrm{n}=91)$. The tumor samples were further stratified based on tumor staging into NMIBC and MIBC (Figure 2). X-linked CpGs and those with a poor signal (defined by a detection p-value of $>0.05$ ) were eliminated, which left 1,303 sites for analysis (Additional file 1: Table S1). A supervised cluster analysis of $\mathrm{N}$ versus $\mathrm{CN}$ and $\mathrm{T}$ samples revealed UC-specific DNA methylation alterations, of which 158 were hypermethylated CpG sites and 356 were hypomethylated sites $(\mathrm{p}<0.001)$ (Figure 2, Additional file 2: Table S2). In these loci, we selected top $30 \mathrm{CpG}$ sites from the statistical results which showed lesser p-value both between $\mathrm{N}$ and $\mathrm{CN}$, also $\mathrm{CN}$ and $\mathrm{T}$. We verified DNA methylation status using the same training sets by PSQ and compared with GoldenGate data. Finally, we identified the $12 \mathrm{CpG}$ sites (5 were hyper methylated and 7 were hypomethylated) from 11 genes, of which quantification of DNA methylation status were well accorded with GoldenGate data (Table 3). We also identified the top $13 \mathrm{CpG}$ sites which distinguished $\mathrm{N}$ from $\mathrm{CN}$. Then PSQ was performed on DNA samples allocated to the tissue validation set (Table 1: $21 \mathrm{Ns}, 25 \mathrm{CNs}$ and $53 \mathrm{Ts}$ ) and urine validation sets (Table 1: 18 urine sediments from healthy volunteers (NUs) and 73 urine sediments from UC patients (TUs)).

\section{Diagnostic accuracy of DNA methylation markers of UC}

In the next step, the sequence-verified loci were tested for diagnostic accuracy by ROC analysis. To determine the diagnostic accuracy for UC tumors, T versus N/CN analysis was performed on 12 CpG loci from 11 genes, of which 5 loci were hypermethylated and 7 hypomethylated (Table 3). The cut-off values to discriminate $\mathrm{T}$ from N/CN using each marker were determined from the ROC curves as the maximum values of sensitivity and specificity, as follows: [sensitivity (\%) + specificity (\%) - 100]. For all 12 loci, there was a statistically significant and dramatic distinction in DNA methylation levels between $\mathrm{N} / \mathrm{CN}$ and $\mathrm{T}$. The ranges for area under the curve (AUC), sensitivity and specificity were 0.85$0.97,75.0-94.34 \%$ and $84.44-100 \%$ respectively (Table 3 ). In particular, combination analysis of $S O X 1$ and VAMP8 could distinguish $\mathrm{T}$ from N/CN with $100 \%$ sensitivity and specificity (data not shown). Interestingly, DNA methylation levels in $\mathrm{CN}$ samples were not correlated with their respective $\mathrm{T}$ samples, and DNA methylation levels in $\mathrm{T}$ samples did not correlate with age, gender and stage for all 12 markers.

To determine the diagnostic accuracy of epigenetic field defect, ROC analysis was performed for the tissue samples, $\mathrm{N}$ versus $\mathrm{CN}$, using 13 markers from 13 genes, of which 10 were hypermethylated and 3 hypomethylated 
Table 2 Primer sequences for PSQ

\begin{tabular}{|c|c|c|c|c|c|c|}
\hline Gene & Annotation & Forward & Reverse & Sequencing & Sequence analyzed & $\begin{array}{l}\text { Amplicon location relative } \\
\text { to transcription start site }\end{array}$ \\
\hline SOX1 & $\begin{array}{l}\text { Sex determining region } \\
\text { Y box1 }\end{array}$ & GGTATTTGGGATTAGTATATGTTTAG & СТАТСТССТТССТСТАС & TTAGTATATGTTTAG & CGTACGCGGCGCGTCG & $-462 \sim-351$ \\
\hline TJP2 & Tight junction protein 2 & GGTTTTAAGATAGGATTTAAAATTTGAG & CAAAACCTCACACAAACAACTTC & AGGTTTTTTAAGTT & CGATTTTCG & $-492 \sim-409$ \\
\hline MYOD1 & $\begin{array}{l}\text { Myogenic } \\
\text { differentiation } 1\end{array}$ & GTGGGTATTTAGATTGTTAGTA & ACAATAACTCCATATCCTAAC & GAAGTTAGGAT & CGTGTCGCGTTATCG & $+96 \sim+233$ \\
\hline HOXA9_1 & Homeo box A9 & TTGTTTAATTTATGTGAGGGGTT & САAATCTAACCTTATCTCTATACTCTCCC & TGATATAAAATAGTT & CGTTAAG & $-397 \sim-243$ \\
\hline HOXA9_2 & Homeo box A9 & ATGAAATTTGTAGTTTATAAATTT & ATTACCCAAAACCCCAATAATAAC & GTTTATAATITT & CGTGGGTCGGGTCGGGCGG & $+10 \sim+100$ \\
\hline GALR1 & Galanin receptor 1 & ATTAATGGA TGAGGAGGTT & ATACCAAAAA CTTCTCTACT AC & GTGATTITA AGGGG & CGCGGATTIT AGTCGAGTTG & $-194 \sim+110$ \\
\hline IPF1 & $\begin{array}{l}\text { Insulin promoter } \\
\text { factor } 1\end{array}$ & GTAGTITAA GAGGAAGG & AAAAATTAAA ACCCATTTAA CCAA & $\begin{array}{l}\text { GTAGTTTAAA } \\
\text { GAGGAAGGT }\end{array}$ & CGCGTITIIITITTCGTTG & $-786 \sim-702$ \\
\hline TAL1 & $\begin{array}{l}\text { T-cell acute } \\
\text { lymphocytic leukemia } 1\end{array}$ & GTAAATAGAA GGAGGTTTT & ACACTACTIT CAAAAATATA AC & AGAA GGAGGTITI & $\begin{array}{l}\text { CGTAG TTAATTTAAG } \\
\text { ATTCG }\end{array}$ & $-613 \sim-470$ \\
\hline EYA4 & Eyes absent homolog 4 & GGATGTTTGTTITTATTAGAGGTATAG & ААТТСТСТСААСТСАААСТССС & GAAGGGGAAATTT & CGATATTGGAAGGAACG & $+252 \sim+457$ \\
\hline $\mathrm{CDH} 13$ & Cadherin 13 & AGTTIAAAGAAGTAAATGGGATGTTA & СTTCCCAAATAAATCAACAACAAC & ATTTGTATGTAAAA & CGAGGGAGCGT & $-175 \sim+6$ \\
\hline CYP1B & $\begin{array}{l}\text { Cytochrome P450 } \\
\text { family } 1\end{array}$ & GTTTGATITGGAGTGGGAGT & СТACCCTTAAAAACCTAACAAAATC & AGGGTATGGGAATTGA & CGTTATTTATCGA & $+26 \sim+178$ \\
\hline NPY & Neuropeptide Y & $\begin{array}{l}\text { GGGTTGTTIT TATTITTGGT } \\
\text { AGGATTAGA }\end{array}$ & CACCAAAACC CAAATATCTA CCC & AGGAAAGTAGGGAT & CGGGT ATTGTTCGAG & $-353 \sim-253$ \\
\hline VAMP8 & $\begin{array}{l}\text { Vesicle-associated } \\
\text { membrane protein } 8\end{array}$ & AAGTTITGT TTGGGAAGTT ATT & CATATCTCAA AACAACCCAA & $\begin{array}{l}\text { GTTAGGTGTG } \\
\text { GTTGGAG }\end{array}$ & CGATTCGAGATGCGAGGTGG & $-157 \sim+56$ \\
\hline CASP8 & Caspase 8 & GAAGTTTGATTTTGTTGGTTTAAAA & САACCTCTCTAACTAAACCСТCCTT & TGTTTAGAGGTTG & CGGGTTGCGGGT & $+431 \sim+533$ \\
\hline SPP1 & $\begin{array}{l}\text { Secreted } \\
\text { phosphoprotein } 1\end{array}$ & GGAATAAGGA TAGGTAGGT & $\begin{array}{l}\text { CAAAATAACT ACTTAAAAAA } \\
\text { ACTACTTCAA }\end{array}$ & $\begin{array}{l}\text { GAATAAGGAT } \\
\text { AGGTAGGTTG GG }\end{array}$ & CGATTTGTTTAAGGTTGTAT & $+99 \sim+117$ \\
\hline CAPG & Capping protein & GGGGTAGGTTGGAAGGAAGA & ACAACCACCCTACCACCTTCA & GTTGGAAGGAAGA & CGAATTTACGAAGT & $+200 \sim+294$ \\
\hline RIPK3 & $\begin{array}{l}\text { Receptor-interacting } \\
\text { serine-threonine } \\
\text { kinase } 3\end{array}$ & GTTTTGGAA GGTGAGGAT & AAAACTAATA CCTITCTCCT TAACT & ATTTAATT TGGTTG & $\begin{array}{l}\text { CGGT AGGTGTTTAG } \\
\text { GAAACG }\end{array}$ & $-137 \sim-27$ \\
\hline IFNG & $\begin{array}{l}\text { Interferon gamma } \\
\text { receptor } 1\end{array}$ & AATAGTATTTGTTTGTGGTTGAA & TAACACCAAATCTCAAAATAACT & GAAAATGATTGAATAT & CGATTTG & $+257 \sim+359$ \\
\hline HLADPA1 & $\begin{array}{l}\text { Major histocompatibility } \\
\text { complex, class II, } \\
\text { DP alpha } 1\end{array}$ & AATTITGAAAATGAATTGTGAATTG & САТТСТСТАТTACTAAATAAAAAAAAC & GAGTIIITTGATTA & CGTTGGTA & $-74 \sim+38$ \\
\hline
\end{tabular}




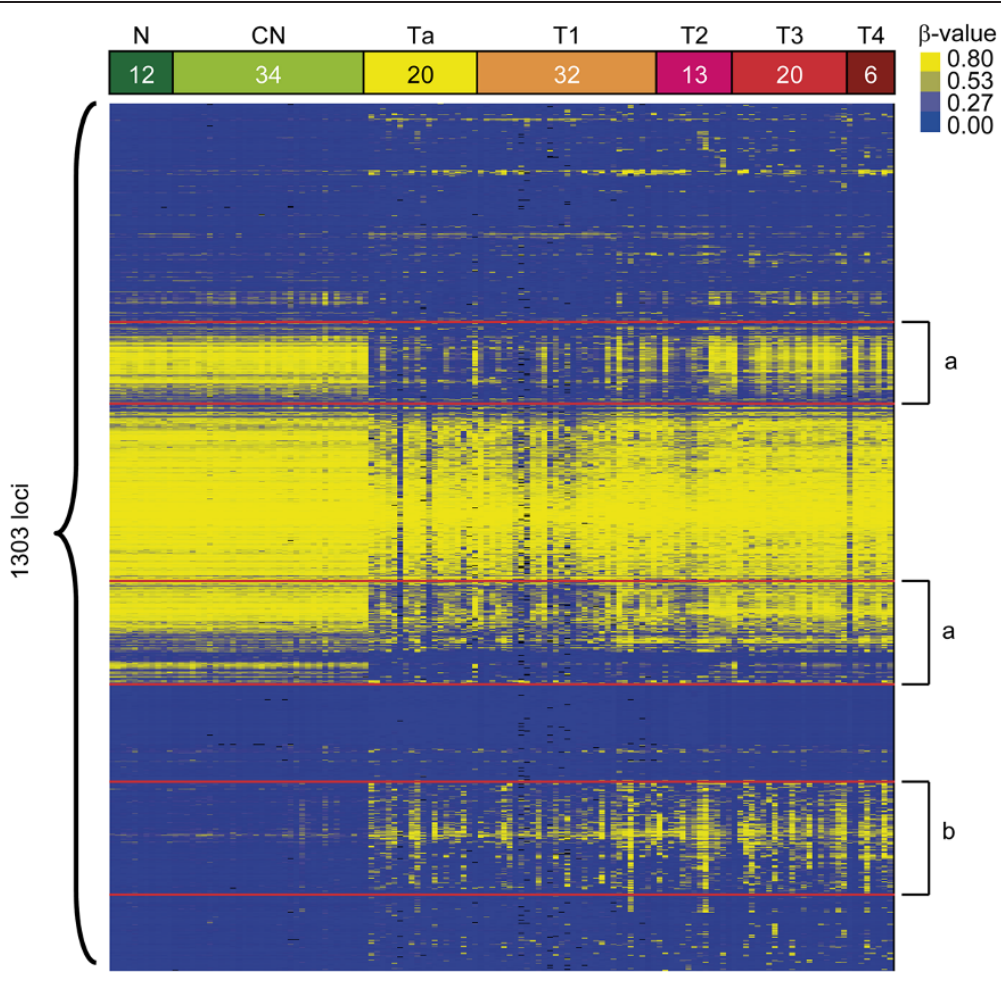

Figure 2 Global DNA methylation alterations in UC. Supervised cluster analysis of 1,303 loci (784 genes) from bladder samples, using the Illumina GoldenGate methylation assay. N $(n=12)$ represents normal tissue from patients without urothelial cancer $(U C)$; $C N(n=34)$ represents corresponding normal-appearing tissue from UC patients; Ta-T1 $(n=49)$ represents non-muscle-invasive bladder cancer; and T2-T4 $(n=38)$ represents muscle-invasive bladder cancer. No methylation is shown in blue, and increasing DNA methylation is shown in yellow. (a) UC-specific hypomethylated CpG sites, and (b) UC-specific hypermethylated CpG sites.

(Table 3). The ranges for AUC, sensitivity and specificity were $0.73-0.93,56.0-88.0 \%$, and $71.43-100 \%$, respectively (Table 3).

Diagnostic accuracy for UC as measured by DNA methylation in urine samples was evaluated based on the same 12 loci as for tissue samples, and determined by ROC analysis on NU versus TU urine samples. For all 12 markers, DNA methylation levels in TUs were statistically significantly distinct from those in CUs. The ranges of AUC, sensitivity and specificity were $0.67-0.93$, $41.54-97.06 \%$, and $40.0-100 \%$ respectively (Table 3). Among the loci examined here, values for AUC corresponding to urine samples were lower than those corresponding to urothelial tissues, except for the loci $M Y O D$ and HOXA9_1. Also the cut-off value which distinguishes TU from NU in both hyper- and hypo- methylated markers were lower in urine than in the tissue for all cancer types, except in IFNG. These results suggested that either the copy number of methylated CpG loci in urine sediments was difficult to be detected because of low DNA quality, or the concentration of cancer cells were diluted by the presence of other unrelated cells in the urine.

Representative scatter plots for 2 hypermethylated loci (SOX1 and HOXA9_2) and 2 hypomethlated loci (IFNG and SPP1) examined in the various tissue and urine samples are shown (Figure 3).

The DNA methylation data were analyzed for each tissue/urine sample to determine the number of loci for which a given sample was considered a true positive based on the respective cut-off value (Table 4). Thus, out of the $53 \mathrm{~T}$ samples, 50 were positive for at least 6 and more loci. On the other hand, there were $3 \mathrm{~T}$ samples that were false negative for some loci and there was $1 \mathrm{~N} / \mathrm{CN}$ sample that was false positive for some loci. Most tumor samples were positive for at least 6 markers. In other words, true-positive levels of DNA methylation for 6 or more markers allowed clear discrimination between $\mathrm{T}$ and N/CN samples with $94.3 \%$ sensitivity and 97.8\% specificity (Table 4 top). For distinguishing between cancerous and non-cancerous tissue, the 13 loci selected for comparing $N(n=21)$ with $C N$ samples $(n=25)$ were examined for each tissue sample. All the normal samples were positive for a maximum of 6 loci, while a majority of the $\mathrm{CN}$ samples were positive for at least 8 loci. Hence, for samples that showed altered DNA methylation for 7 or more markers, $\mathrm{N}$ could be discriminated from $\mathrm{CN}$ with $76.0 \%$ sensitivity and $100 \%$ specificity (Table 4 middle; false negative: $6 / 25$; false positive: $0 / 21$ ). In the case of 
Table 3 ROC analysis of DNA methylation markers for UC

\begin{tabular}{lccccc}
\hline Gene & $\begin{array}{c}\text { Cut-off } \\
\text { value (\%) }\end{array}$ & AUC & $\begin{array}{c}\text { Sensitivity } \\
(\%)\end{array}$ & $\begin{array}{c}\text { Specificity } \\
(\%)\end{array}$ & $\begin{array}{c}\mathbf{P} \\
\text { value }\end{array}$ \\
\hline $\begin{array}{l}\text { Validation in tissue } \\
\text { (N/CN vs. T) }\end{array}$ & & & & & \\
Hypermethylation & & & & & \\
$\quad$ SOX1 & 32.59 & 0.97 & 93.62 & 97.5 & $5.13 \mathrm{E}-14$ \\
TJP2 & 71.42 & 0.92 & 84.91 & 97.78 & $1.19 \mathrm{E}-12$ \\
MYOD & 26.0 & 0.91 & 75.0 & 79.83 & $1.73 \mathrm{E}-12$ \\
HOXA9_1 & 55.59 & 0.86 & 76.6 & 97.83 & $9.00 \mathrm{E}-08$ \\
HOXA9_2 & 29.06 & 0.86 & 83.02 & 97.83 & $5.22 \mathrm{E}-10$ \\
Hypomethylation & & & & & \\
VAMP8 & 12.5 & 0.96 & 94.34 & 97.83 & $2.22 \mathrm{E}-15$ \\
CASP8 & 23.18 & 0.96 & 94.34 & 95.65 & $4.88 \mathrm{E}-15$ \\
SPP1 & 26.14 & 0.95 & 86.79 & 100 & $1.49 \mathrm{E}-14$ \\
IFNG & 64.7 & 0.93 & 82.98 & 95.65 & $2.16 \mathrm{E}-12$ \\
CAPG & 16.21 & 0.93 & 83.02 & 95.65 & $1.08 \mathrm{E}-12$ \\
HLADPA1 & 14.31 & 0.88 & 84.62 & 86.96 & $1.06 \mathrm{E}-09$ \\
RIPK3 & 22.97 & 0.85 & 81.63 & 84.44 & $9.54 \mathrm{E}-07$ \\
Validation & & & &
\end{tabular}

Validation in tissue ( $\mathrm{N}$ vs. $\mathrm{CN}$ )

Hypermethylation

$\begin{array}{lccccc}\text { SOX1 } & 16.51 & 0.86 & 68.18 & 100 & 9.04 \mathrm{E}-05 \\ \text { MYOD } & 12.71 & 0.85 & 76.0 & 85.71 & 5.19 \mathrm{E}-05 \\ \text { HOXA9_1 } & 22.95 & 0.80 & 76.0 & 80.95 & 0.00043 \\ \text { GALR1 } & 7.24 & 0.85 & 76.0 & 85.71 & 4.26 \mathrm{E}-05 \\ \text { IPF1 } & 33.83 & 0.74 & 64.0 & 76.19 & 0.0089 \\ \text { TAL1 } & 29.47 & 0.83 & 76.0 & 85.71 & 0.00011 \\ \text { EYA4 } & 6.38 & 0.80 & 83.33 & 73.68 & 0.0078 \\ \text { CDH13 } & 7.13 & 0.93 & 88.0 & 85.71 & 5.24 \mathrm{E}-07 \\ \text { CYP1B } & 13.61 & 0.75 & 60.0 & 80.95 & 0.0040 \\ \text { NPY } & 10.31 & 0.82 & 88.0 & 71.43 & 0.00018 \\ \text { Hypometylation } & & & & & \\ \text { CASP8 } & 46.38 & 0.73 & 60.0 & 85.71 & 0.0084 \\ \text { IFNG } & 84.93 & 0.78 & 56.0 & 95.24 & 0.001 \\ \text { HLADPA1 } & 24.27 & 0.83 & 72.0 & 85.71 & 0.00011\end{array}$

Validation in urine sediment (NU vs. TU)

Hypermethylation

$\begin{array}{lccccc}\text { SOX1 } & 15.62 & 0.74 & 41.54 & 100 & 0.0041 \\ \text { TJP2 } & 7.933 & 0.79 & 92.54 & 56.25 & 0.0003 \\ \text { MYOD } & 9.897 & 0.93 & 86.79 & 87.50 & 3.10 \mathrm{E}-05 \\ \text { HOXA9_1 } & 7.038 & 0.92 & 86.23 & 88.89 & 4.25 \mathrm{E}-05 \\ \text { HOXA9_2 } & 3.20 & 0.81 & 88.57 & 61.54 & 0.0004 \\ \text { Hypomethylation } & & & & & 10.78 \\ \text { VAMP8 } & 10.78 & 0.72 & 97.06 & 40.0 & 0.023 \\ \text { CASP8 } & 7.863 & 0.82 & 73.61 & 76.92 & 0.0005 \\ \text { SPP1 } & 21.23 & 0.79 & 85.94 & 75.0 & 0.0015\end{array}$




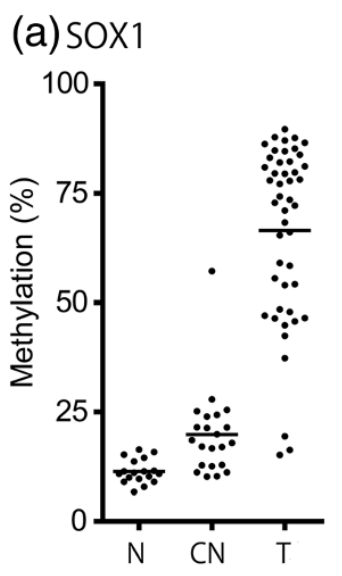

(c) IFNG

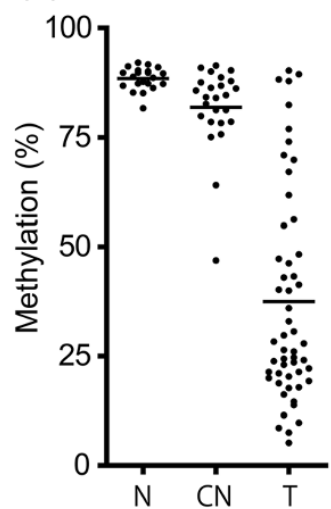

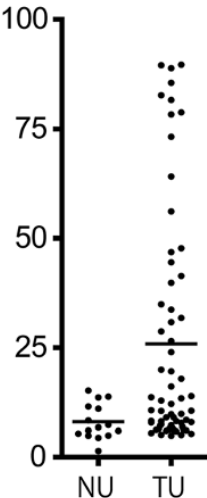

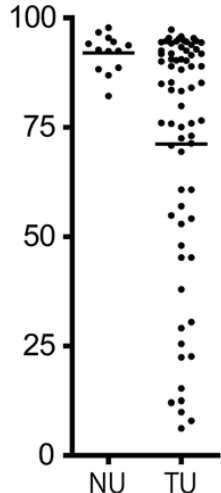

(b) HOXA9_2

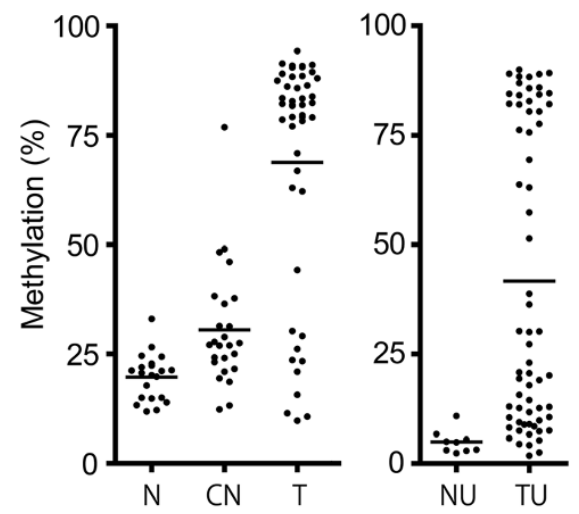

(d) SPP1

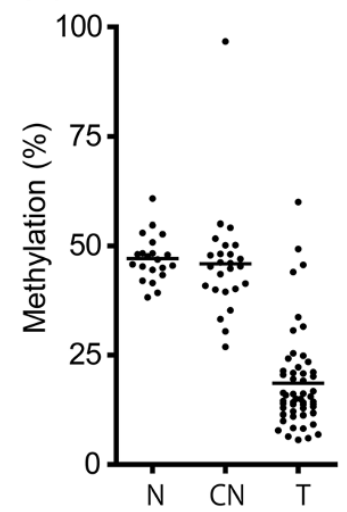

Figure 3 Differential DNA methylation at CpG sites. Scatter plots of quantitative DNA methylation analysis by PSQ in select loci that were hypermethylated: (a) SOX1 (b) HOXA9_X2; or hypomethylated: (c) IFNG (d) SPP1. Mann-Whitney U test was used to compare quantitative methylation levels between the 2 groups. Short horizontal lines represent the median.

hand, increasing the number of markers increases the sensitivity, albeit at the cost of specificity.

In this study, we identified a panel of loci with UCspecific alterations in DNA methylation. The study design included 3 steps for identification and validation of these loci analyzed in urothelial tissue or urine samples (Figure 1). In the first step, high-throughput DNA methylation profiling revealed a total of $514 \mathrm{CpG}$ sites that caused UCspecific aberrant methylation with statistical significance ( $\mathrm{p}<0.001$ ). This corresponds to $39.4 \%$ of $\mathrm{CpG}$ sites assayed by the Bead $^{\mathrm{m}}$ array and suggested genome-wide UCspecific DNA methylation. Furthermore, normal tissue and normal-appearing tissue adjacent to UC patients were found to be significantly different with regard to 39 hypermethylated sites and 7 hypomethylated sites. These CpG sites could also be used to diagnose UC risk. (data not shown). These results indicated that aberrant DNA methylation in UC already occurred in non-cancerous epithelia in UC patients, supporting the notion that DNA methylation alterations occur gradually during the multistep process of carcinogenesis.
The DNA methylation status of the various CpG sites identified from Bead $^{\mathrm{TM}}$ array data as UC-specific was sequence verified by PSQ. Next, we evaluated the diagnostic accuracy of $12 \mathrm{CpG}$ sites. Interestingly, most of these loci were in genes that have not been reported for their aberrant DNA methylation in UC, except CASP8 [23]. Since these CpG sites were identified from the clustering data in the comparison of normal and cancerous tissues, DNA methylation levels assayed by PSQ represented the fraction of methylated DNA clones in a sample, proportional to the number of malignant cells, if the tumor heterogeneities are ignored. In the tissue analysis, DNA methylation level between N/CN and T could be clearly discriminated for each marker, and the combination analysis of all 12 markers provided accuracy, 94.3\% sensitivity, and $97.8 \%$ specificity (Table 4). Furthermore, $\mathrm{CN}$ could be discriminated from $\mathrm{N}$ with $76.0 \%$ sensitivity and $100 \%$ specificity. These results indicate that UC-specific aberrant DNA methylation also occurred in the adjacent normal epithelia, but at a lower level than in the tumor. In this way, the quantitative 
Table 4 Diagnostic accuracy of the panel markers for UC

\begin{tabular}{|c|c|c|c|c|}
\hline & \multicolumn{2}{|c|}{ Aberrant methylation } & \multirow[t]{2}{*}{ Sensitivity (\%) } & \multirow[t]{2}{*}{ Specificity (\%) } \\
\hline & Less than 5 & 6 and more & & \\
\hline $\mathrm{N} / \mathrm{CN}$ & 45 & 1 & 94.3 & 97.8 \\
\hline \multirow[t]{3}{*}{$\mathrm{T}$} & 3 & 50 & & \\
\hline & \multicolumn{2}{|c|}{ Aberrant methylation } & Sensitivity (\%) & Specificity (\%) \\
\hline & Less than 6 & 7 and more & & \\
\hline $\mathrm{N}$ & 21 & 0 & 76 & 100 \\
\hline \multirow[t]{3}{*}{$\mathrm{CN}$} & 6 & 19 & & \\
\hline & \multicolumn{2}{|c|}{ Aberrant methylation } & Sensitivity (\%) & Specificity (\%) \\
\hline & Less than 5 & 6 and more & & \\
\hline NU & 18 & 0 & 100 & \\
\hline TU & 0 & 73 & 100 & 100 \\
\hline
\end{tabular}

Abbreviations: $N$ normal urothelial tissue, $C N$ corresponding normal-appearing tissue adjacent to the tumor in UC patients, $T$ tumor tissue, $N U$ urine sediments from healthy volunteers. TU urine sediments from UC patients.

methylation analysis has an advantage in detecting field defect, which is a useful indicator for determining UC risk or predicting recurrence. Aberrant DNA methylation of TJP2, SPP1, and IFNG did not show a statistically significant difference between $\mathrm{N}$ and $\mathrm{CN}$ (data not shown), although these epigenetic alterations are thought to be cancer-specific and a part of the multistep carcinogenesis. Interestingly, TJP2 (tight junction protein) is located on chromosome 9 (9q21.11), which shows allelic loss in UC most frequently. Allelic loss on chromosome 9 was thought to be the earliest genetic event arising in UC; however, we previously reported that allelic loss on $9 \mathrm{q}$ had not occurred in tissue showing dysplasia and adjacent normal urothelia of UC patients [19]. Taking into consideration these genetic and epigenetic alterations in adjacent normal urothelia, the alteration on $9 \mathrm{q}$ might be a truly tumor-specific event.

In the urine analysis, the combination of 12 markers provided sufficient accuracy to discriminate TU from NU, with $100 \%$ sensitivity and $100 \%$ specificity, and indicated a higher detection value for UC than so far reported for DNA methylation marker panels using quantitative analysis [13,14]. However, compared with the tissue analysis, the diagnostic power of each marker was not sufficient, and data from all 12 markers were required for a true diagnosis.

To determine whether the aberrantly methylated loci might play a functional role in tumorigenesis, we compared 4 genes expression to DNA methylation levels. In our results, a hypermethylated gene, SOX1 expression reduced in tumor tissue, whereas TJP2 expression did not reduce. In a recent study by Dudziec E. et al. [24], a large scale profiling among DNA methylation, histone modification and gene expression using UC cells revealed that $20-30 \%$ genes were silenced by epigenetic regulation. In this way, aberrant regional hypermethylation in cancer cells do not always regulate gene expression, and the hypermethylated loci that identified in this study might be a hallmark of cancer. In contrast to promoter hypermethylation, hypomethylation-dependent transcriptional activation in cancer is less frequent [25]. Currently, major contribution of global hypomethylation especially in retrotransposons and pericentromeric repeats are thought to be the enhancement of genomic instability [26]. Interestingly, hypomethylation of VAMP8 and SPP1 correlated with the gene expression significantly. Furthermore DNA methylation levels of $S P P 1$ inversely associated with expression levels. Several studies showed some transcription control regions, with the hypormethylated and activated in cancer $[27,28]$ (Although we examined only 4 genes, our results might support these phenomena. Further studies needs to clarify the association aberrant DNA methylation with gene expression in cancer.

A limitation of this study is that candidate UC-specific DNA methylation loci were identified using tissue samples in the first step, and these markers showed a poorer diagnostic sensitivity in urine than in tissue samples. However, urine sediments from the healthy population sometimes show aberrant DNA methylation that is unrelated to cancer, and cluster analysis to identify DNA methylation loci by just urine samples may reflect the etiology of UCs. Another limitation is small numbers of each step. Also the consecutive concordant study that revealed DNA methylation status of $\mathrm{T}, \mathrm{CN}$ and $\mathrm{TU}$ samples in one person including follow-up urines.

\section{Conclusions}

In conclusion, by a genome-wide analysis, markers based on DNA methylation were identified for high accuracy of diagnosis of UCs using urine samples in our preliminary study. These markers will need to be validated in a larger scale study. In the future, it may be possible to develop a panel of carefully selected DNA methylation markers for use on urine sediments to detect both primary UCs and recurrent UCs. In this way, DNA methylation profiling might be a useful tool to discriminate several clnicopathological factor of UCs and to clarify the multi-step carcinogenesis of UCs.

\section{Additional files}

Additional file 1: Table S1. All data of universal beads ${ }^{\mathrm{TM}}$ array.

Additional file 2: Table S2. Aberrant DNA methylated loci obtained from beads ${ }^{\mathrm{TM}}$ array.

Additional file 3: Figure S3. Correlation between gene expression and DNA methylation levels in normal and UC tissues.Five normal urothelial tissues (N) and 53 tumor tissues (T) (Stage, Ta: 13, T1: 21, T2: 7, T3: 10, T4: 2, Grade, G1: 2, G2: 25, G3: 26) were analyzed. Immunohistocheistry (IHC) 
(left) represents corresponding median $\mathrm{IHC}$ score in each group. Original magnification, $\times 200$. Expression of 4 genes in normal and tumor tissues were shown in Scatter plots (middle). Mann-Whitney $U$ test was used to compare quantitative methylation levels between the 2 groups. Short horizontal lines represent the median. Pearson's correlation coefficient between IHC score and DNA methylation levels (right). Blue circles represent normal tissues.

\section{Competing interests}

The authors declare that they have no competing interests.

\section{Authors' contributions}

YC conceived of the study, participated in its design and coordination and drafted the manuscript. YK and HF collected UC samples and gain ethics committee approval to enroll this study at National Cancer Center Hospital Tokyo Japan. YK also helped to performed PSQ experiments. KS and KK collected UC samples and gain ethics committee approval to enroll this study at Tochigi Cancer Center Hospital, Utsunomiya Japan. GL and PAJ participated in the design, helped to perform statisitical analysis and collected UC samples and gain ethics committee approval to enroll this study at USC, LA, USA. KF and YH collected UC and healthy urine samples, and gain ethics committee approval to enroll this study at Nara medical university, Kashihara, Japan. HK participated in writing of the manuscript. All authors read and approved the final manuscript.

\section{Acknowledgements}

This work was supported in part by a Grant-in-Aid for Scientific Research 22791508 to YC from the Japan Society for the Promotion of Science, Japan.

\section{Author details}

'Department of Molecular Pathology, Nara Medical University, 840, Shijyo-cho, Kashihara, Japan. ${ }^{2}$ Department of Urology, Nara Medical University, 840, Shijyo-cho, Kashihara, Japan. ${ }^{3}$ Division of Molecular Pathology, National Cancer Center Research Institute, 5-1-1, Tsukiji Chuo-ku, Tokyo, Japan. ${ }^{4}$ Department of Urology, National Cancer Center Hospital, 5-1-1, Tsukiji, Chuo-ku, Tokyo, Japan. ${ }^{5}$ Oncogene Research Unit/Cancer Prevention Unit, Tochigi Cancer Center Research Institute, 4-9-13, Yonan, Utsunomiya, Japan. ${ }^{6}$ Department of Urology, Tochigi Cancer Center Hospital, 4-9-13, Yonan, Utsunomiya, Japan. 'Department of Urology, Norris Comprehensive Cancer Center, University of Southern California, 1441 Eastlake Ave, Los Angeles, CA, 90033, USA.

\section{Received: 17 February 2013 Accepted: 22 May 2013}

Published: 4 June 2013

\section{References}

1. Siegel R, Naishadham D, Jemal A: Cancer statistics, 2013. CA Cancer I Clin 2013, 63:11-30.

2. Sugano K, Kakizoe T: Genetic alterations in bladder cancer and their clinical applications in molecular tumor staging. Nat Clin Pract Urol 2006, 3:642-652.

3. Knowles MA: What we could do now: molecular pathology of bladder cancer. Mol Pathol 2001, 54:215-221.

4. Van Rhijn BW, van der Poel HG, van der Kwast TH: Urine markers for bladder cancer surveillance: a systematic review. Eur Urol 2005, 47:736-748.

5. Goessl C, Müller M, Straub B, Miller K. DNA alterations in body fluids as molecular tumor markers for urological malignancies. Eur Urol 2002, 41:668-676.

6. Jones PA, Laird PW: Cancer epigenetics comes of age. Nat Genet 1999, 21:163-167.

7. De Smet C, Loriot A, Boon T: Promoter-dependent mechanism leading to selective hypomethylation within the 5 region of gene MAGE-A1 in tumor cells. Mol Cell Biol 2004, 24:4781-4790.

8. Yates DR, Rehman I, Meuth M, Cross SS, Hamdy FC, Catto JW: Methylational urinalysis: a prospective study of bladder cancer patients and age stratified benign controls. Oncogene 2006, 25:1984-1988

9. Dhawan D, Hamdy FC, Rehman I, Patterson J, Cross SS, Feeley KM, Stephenson Y, Meuth M, Catto JW: Evidence for the early onset of aberrant promoter methylation in urothelial carcinoma. J Pathol 2006, 209:336-343.

10. Esteller M, Corn PG, Baylin SB, Herman JG: A gene hypermethylation profile of human cancer. Cancer Res 2001, 61:3225-3229.
11. Yu J, Zhu T, Wang Z, Zhang H, Qian Z, Xu H, Gao B, Wang W, Gu L, Meng J, Wang J, Feng $X$, Li Y, Yao $X$, Zhu J: A novel set of DNA methylation markers in urine sediments for sensitive/specific detection of bladder cancer. Clin Cancer Res 2007, 13:7296-7304.

12. Chan MW, Chan LW, Tang NL, Tong JH, Lo KW, Lee TL, Cheung HY, Wong WS, Chan PS, Lai FM, To KF: Hypermethylation of multiple genes in tumor tissues and voided urine in urinary bladder cancer patients. Clin Cancer Res 2002, 8:464-470.

13. Friedrich MG, Weisenberger DJ, Cheng JC, Chandrasoma S, Siegmund KD, Gonzalgo ML, Toma MI, Huland H, Yoo C, Tsai YC, Nichols PW, Bochner BH, Jones PA, Liang G: Detection of methylated apoptosis-associated genes in urine sediments of bladder cancer patients. Clin Cancer Res 2004, 10:7457-7465.

14. Hoque MO, Begum S, Topaloglu O, Chatterjee A, Rosenbaum E, Van Criekinge W, Westra WH, Schoenberg M, Zahurak M, Goodman SN, Sidransky D: Quantitation of promoter methylation of multiple genes in urine DNA and bladder cancer detection. J Natl Cancer Inst 2006, 98:996-1004.

15. Vinci S, Giannarini G, Selli C, Kuncova J, Villari D, Valent F, Orlando C: Quantitative methylation analysis of BCL2, hTERT, and DAPK promoters in urine sediment for the detection of non-muscle-invasive urothelial carcinoma of the bladder: A prospective, two-center validation study. Urol Oncol 2011, 29:150-156.

16. Nakajima T, Yamashita S, Maekita T, Niwa T, Nakazawa K, Ushijima T: The presence of a methylation fingerprint of Helicobacter pylori infection in human gastric mucosae. Int J Cancer 2009, 124:905-910.

17. Wolff EM, Chihara Y, Pan F, Weisenberger DJ, Siegmund KD, Sugano K, Kawashima K, Laird PW, Jones PA, Liang G: Unique DNA methylation patterns distinguish noninvasive and invasive urothelial cancers and establish an epigenetic field defect in premalignant tissue. Cancer Res 2010, 70:8169-8178.

18. Hemanek PS, Sobin LH: UICC-International Union Against Cancer. TNM classification of malignant tumors. 4th edition. Heidelberg, Germany: Springer-Verlag; 1987.

19. Chihara $Y$, Sugano $K$, Kobayashi A, Kanai $Y$, Yamamoto H, Nakazono M, Fujimoto H, Kakizoe T, Fujimoto K, Hirohashi S, Hirao Y: Loss of blood group A antigen expression in bladder cancer caused by allelic loss and/ or methylation of the ABO gene. Lab Invest 2005, 85:895-907.

20. Allred DC, Harvey JM, Berado M, Clark GM: Prognostic and predictive factors in breast cancer by immunohistochemical analysis. Mod Pathol 1998, 11:155-168.

21. Negraes PD, Favaro FP, Camargo JL, Oliveira ML, Goldberg J, Rainho CA, Salvadori DM: DNA methylation patterns in bladder cancer and washing cell sediments: a perspective for tumor recurrence detection. BMC Cancer 2008, 8:238.

22. Wolff EM, Liang G, Cortez CC, Tsai YC, Castelao JE, Cortessis VK, Tsao-Wei DD, Groshen S, Jones PA: RUNX3 methylation reveals that bladder tumors are older in patients with a history of smoking. Cancer Res 2008, 68:6208-6214.

23. Christoph F, Weikert S, Kempkensteffen C, Krause H, Schostak M, Miller M, Schrader M: Regularly methylated novel pro-apoptotic genes associated with recurrence in transitional cell carcinoma of the bladder. Int $\mathrm{J}$ Cancer 2006, 119:1396-1402.

24. Dudziec E, Gogol-Döring A, Cookson V, Chen W, Catto J: Integrated epigenome profiling of repressive histone modifications, DNA methylation and gene expression in normal and malignant urothelial cells. PLos One 2012, 7:e32750.

25. Rauch TA, Zhong X, Wu X, Wang M, Kernstine KH, Wang Z, Riggs AD, Pfeifer GP: High-resolution mapping of DNA hypermethylation and hypomethylation in lung cancer. Proc Natl Acad Sci USA 2008, 105:252-257.

26. Ehrlich M: DNA hypomethylation in cancer cells. Epigenomics 2009, 1:239-259.

27. Pakneshan P, Tetu B, Rabbani SA: Demethylation of urokinase promoter as a prognostic marker in patients with breast carcinoma. Clin Cancer Res 2004, 10:3035-3041

28. Pulukuri SM, Estes N, Patel J, Rao JS: Demethylation-linked activation of urokinase plasminogen activator is involved in progression of prostate cancer. Cancer Res 2007, 67:930-939.

doi:10.1186/1471-2407-13-275

Cite this article as: Chihara et al.: Diagnostic markers of urothelial cancer based on DNA methylation analysis. BMC Cancer 2013 13:275. 